\title{
LETTER
}

doi:10.1017/S1041610213000227

\section{Patient involvement in research: an audit of study feedback to participants}

The growing importance of involving volunteers and the wider community in research is well recognized. Participants are no longer mere "subjects" but are active partners in the research process, and for these engagements to be successful, effective communication is vital. Researchers are well practiced at disseminating their findings to the wider scientific community, but what are the gold standards when disclosing results, both individual and aggregate, to study participants? Shalowitz and Miller (2008a) emphasize the need to offer research results as an "appropriate and obligatory expression of respect for persons," and the implications of receiving results have been widely examined (Shalowitz and Miller, 2008b; Fernandez et al., 2004). Despite the interest in this area, however, very few studies have looked at dementia research and how best to convey study information and results to participants so as to maximize their involvement and ownership of research. In an attempt to address this gap in the evidence base, we undertook an audit of the views concerning a study newsletter, which had been designed to provide some feedback to those volunteering for the research.

Participants from a UK-based dementia study entitled, "A Study of the Clinical Utility, Patient Preference and Cost Benefit of SPECT and PETCT Brain Imaging in the Evaluation and Diagnosis of Alzheimer's Disease (SUSPECTED-AD)," were invited to complete an evaluation form. The form was posted to participants along with a pre-paid envelope and a copy of the third study newsletter, editions of which had been sent out as hard copies by post at regular six-month intervals during the threeyear study. The newsletter consisted of a single, double-sided, A4 size printed sheet. It contained photos, illustrations, and text detailing both study specific and general information. Topics included information relating to the progress of the study and notification of a forthcoming engagement event; the purpose of the event being to thank personally those who had contributed to the study, to update them about study progress, and, where possible, to offer preliminary study findings. In addition, the newsletter gave details of financial investments in research made locally and information as to how individuals could be further involved in other ongoing research if they wished.

The evaluation form comprised 12 questions exploring views about the newsletter. Specifically, questions were posed about whether participants enjoyed receiving updates and whether they were satisfied with the format, frequency, presentation style, and the tone/language used. Participants were also invited to indicate whether they had any preferences as to the mode by which they received their newsletter (i.e. by post, email, phone, podcast, or other). Questions relating to the content of the newsletter, including a query about future studies and whether volunteers would like feedback from their individual test results, were also posed. In addition, there were open questions relating to the perceived strengths of the newsletter, whether or not it had met with expectations, and how the newsletter might be improved. Of the 84 evaluation forms posted out, $52(62 \%)$ were returned. Of those, $21(40 \%)$ came from caregiver, $11(21 \%)$ from patients, and $12(23 \%)$ from controls. Three $(6 \%)$ returned indicating that the form had been completed by both patient and caregiver, and 5 $(10 \%)$ were returned without any indication of who had completed it.

Results of individual questions are shown in Table 1 (see Table 1, available as supplementary material attached to the electronic version of this paper at www.journals.cambridge.org/jid_IPG). All but one respondent indicated that they had enjoyed receiving the newsletter and all agreed that a newsletter was an appropriate means of giving feedback. The frequency of contact, six-month updates, was generally perceived to be appropriate and of the 35 respondents who expressed a preference, the majority $30(86 \%)$ favored receiving their newsletter by post with $5(14 \%)$ preferring to have their newsletter sent via email to their computer.

To make the newsletter accessible, we had adopted a style and language which we regarded as appropriate. In general, we were successful in this endeavor as it was described as "Well laidout," "informative, in language I can understand," "clear, concise, attractive in appearance...," and the "size of print and layout very easy to read." One respondent commented, however, "a little more detail in layman's terms would be interesting." A thematic evaluation of the free text revealed the perceived strengths of the newsletter to be primarily as a source of information presented in an apposite style, which was of interest, helped the 
participants feel involved and offered hope for the future.

When focusing on whether participants would like feedback about their individual test performance in future research, $44(85 \%)$ individuals responded. Of those, the majority 36 (82\%) affirmed that they would like to be offered personal feedback, $3(7 \%)$ declined, and $5(11 \%)$ were unsure. None of the respondents stated that the newsletter had not met with their expectations, but suggestions for improvements were made. These included making the newsletter more widely available, providing information on sources of help and advice, publishing details of any financial donations made by families who have participated in research, and giving details of the availability of screening tests (if any) for the children of dementia sufferers.

In conclusion, the audit showed that the study newsletter was viewed as a much welcomed part of the research process. It was praised for its content, style, and the regularity of contact (six-month intervals) as well as being generally regarded as an appropriate means by which to feedback results. We would therefore suggest that such newsletters be considered a part of good practice regarding keeping research volunteers informed about their participation. The audit also illustrated areas for improvement. In spite of evidence suggesting that the impact of receiving aggregate results may equal that of receiving individual results (Miller et al., 2008), the majority of respondents from this audit were in favor of receiving individual feedback. This would clearly have cost, ethical, and logistical implications, which, in turn, may have implications for future grant applications. However, if participants' invaluable contribution to the research process is to be acknowledged, this is something that should be addressed for future studies, where this is possible. Connell et al. (2001) advocated disclosing study results as a means of increasing participant recruitment, retention, and overall rates of satisfaction, and in the spirit of engagement, perhaps we require the participants to give some direction as to how this final stage is best delivered.

\section{Conflict of interest}

None.

\section{Description of authors' roles}

Ms. Nicola Barnett is study coordinator for the research and the author of the study newsletter. She is responsible for creating, distributing, and analyzing the questionnaires used in the audit and for writing the submitted letter. Professor John O'Brien is the principal investigator for the study and thus has overall editorial responsibility for all publications relating to this research. The views expressed are those of the authors and not necessarily those of the NHS, the National Institute for Health Research (NIHR), or the Department of Health.

\section{References}

Connell, C. M., Shaw, B. A., Holmes, S. B. and Foster, N. L. (2001). Caregivers' attitudes toward their family members' participation in Alzheimer's disease research: implications for recruitment and retention. Alzheimer's Disease $\mathcal{E}$ Associated Disorders, 15, 137-145.

Fernandez, C. V., Skedgel, C. and Weijer, C. (2004). Considerations and costs of disclosing study findings to research participants. Canadian Medical Association fournal, 170, 1417-1419.

Miller, F. A., Christensen, R., Giacomini, M. and Robert, J. S. (2008). Duty to disclose what? Querying the putative obligation to return research results to participants. Fournal of Medical Ethics, 34, 210-213.

Shalowitz, D. I. and Miller, F. G. (2008a). The search for clarity in communicating research results to study participants. Fournal of Medical Ethics, 34, e17. doi:10.1136/jme.2008.025122.

Shalowitz, D. I. and Miller, F. G. (2008b). Communicating the results of clinical research to participants: attitudes, practices and future directions. PLOS Medicine, 5, e91. doi:10.1371/journal.pmed.0050091.

Nicola A. BarnetT AND John T. O'Brien Institute for Ageing and Health, Newcastle University, Tyne and Wear, UK Email: n.a.barnett@ncl.ac.uk 